\title{
The role of genito-urinary medicine in adolescent sexuality
}

\author{
A A Opaneye, C Willmott
}

\begin{abstract}
Objective-To examine the sexual behaviour and the prevalence of sexually transmitted diseases among adolescent girls who attended the Genito-Urinary Medicine Clinic in Birmingham.

Design-Retrospective case control study. Setting-The Genito-Urinary Medicine Clinic (Ward 19), General Hospital, Birmingham. Subjects-159 adolescent girls aged 13-16 years; $\mathbf{2 1 5}$ female clinic attenders older than 16 years and 55 male partners of the adolescent girls.

Outcome measures-Number of sexual partners; contraceptive practice, and prevalence of sexually transmitted infections.

Results-The number of sexual partners was similar among the girls and controls. More girls than controls did not use any form of contraceptives, $49 \%$ versus $33.5 \%(p<0.01)$. The prevalence of bacterial vaginosis and gonorrhoea was significantly higher in the girls than in the controls $(p<0.05)$. Compared with the girls and controls, the male partners of the adolescents had more sexual partners, and a higher prevalence of sexually transmitted infections- $92.7 \%, 78.6 \%$ and $76.7 \%$ in the males, controls and girls respectively.

Conclusion-The adolescent girls were associating with older men who had many sexual partners, and a higher prevalence of infections. By targetting these girls and their partners for counselling and health education the genitourinary medicine speciality can play a significant and positive role in adolescent sexuality.
\end{abstract}

\section{Introduction}

It is recognised that adolescent girls engage in sexual activities before they are 16 years old, the legal age of consent with consequent risk of acquiring a sexually transmitted disease. ${ }^{1-4}$ Other consequences of

Department of Genitourinary Medicine, The General Hospital, Steelhouse Lane, Birmingham B4 6NH, UK

A A Opaneye, C Willmott adolescent sexuality are unwanted pregnancies and abnormal cervical cytology. ${ }^{56}$ Previous studies have investigated certain groups of young girls in residential care, ${ }^{7}$ pregnant teenagers ${ }^{89}$ or victims of sexual abuse. ${ }^{10}$ The present study reports on adolescent girls and some of their male partners who voluntarily attended the sole genitourinary medicine clinic (GUM Clinic) serving the city of Birmingham.

\section{Materials and methods}

The clinical records of all females aged 13-16 years who voluntarily attended the genitourinary medical clinic at Birmingham between January 1988 and December 1989 were retrospectively reviewed. Victims of rape, sexual assaults and those in residential care were excluded. Details of symptoms, number of sexual partners, contraceptive practice, obstetric history and laboratory findings were recorded on a standardised schedule. The casenotes of their male partners who attended the GUM clinic at Birmingham were also retrospectively reviewed. The 159 adolescent girls were compared with a control group of 215 female clinic attenders. The control group comprised females aged more than 16 years who attended the GUM clinic during a period of two randomly selected weeks in 1989. Statistical analysis by Chi square method and Student's $t$ test.

\section{Results}

There were 7976 new female patients during the period of study. One hundred and fifty nine female adolescents satisfied the criteria and 55 of their male partners were identified. All the adolescent girls were unmarried and seven of them were not sexually active when seen at the clinic. The mean age of the adolescent girls was 15.5 years (range 13-16); for the controls 23.2 years (range 17-54) and for the male partners of the girls it was 21 years (range 15-38). In the preceding three months, $29(18 \%)$ of the adolescents, $29(14 \%)$ of the control females and $30(55 \%)$ of the male partners of the adolescent girls gave a history of multiple sexual partners $(p<0.001)$.

There was no significant difference in the number of sexual partners between the adolescent girls and the control female patients. However, the difference was significant when the girls were compared with their male partners $(p<0.001)$. No girl gave a history of prostitution. 
Table 1 Clinical and laboratory diagnosis

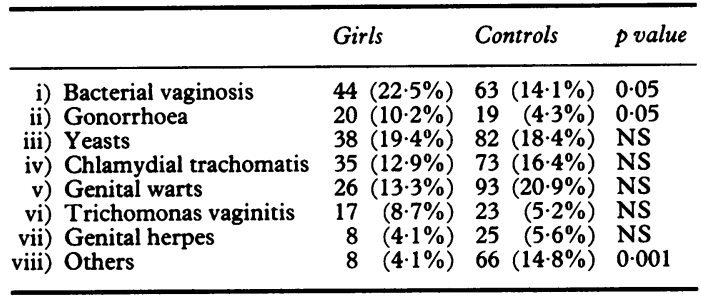

(Some patients had more than one infection).

Seventy eight $(49 \%)$ adolescent girls and 72 $(33.5 \%)$ of the control females were not using any form of contraceptives $(\mathrm{p}<0.01)$. For contraception, $57(36 \%)$ and $24(15 \%)$ of the adolescent girls used the pill and barrier methods respectively. The figures for the control females were $106(49.3 \%)$ and $21(9.8 \%)$ respectively. The commonest findings among the adolescent girls were bacterial vaginosis $(22.5 \%)$ and yeasts $(19.4 \%)$ whereas warts $(20.9 \%)$ and yeasts $(18.4 \%)$ were the commonest among the control female clinic attenders (table 1). In the male partners of the adolescent girls, the incidences of gonorrhoea; non-gonococcal urethritis and genital warts were $32 \cdot 7 \%, 52.7 \%$ and $20 \%$ respectively.

In the study population, the prevalence rates of genital infections were $75 \%$ for the adolescent girls, $78 \%$ for the control females and $92 \%$ for the male partners of the adolescent girls. The difference in rates between the adolescent girls and their male partners was statistically significant (table 2 ).

\section{Discussion}

In 1985 it was reported from a London clinic ${ }^{11}$ that there was a decline in the prevalence of sexually transmitted diseases. Recently in a study of cohorts of college women over a period of 15 years, it was concluded that there has been little change in sexual behaviour despite new and serious epidemics of sexually transmitted diseases. ${ }^{12}$ One useful role of the GUM speciality in adolescent sexuality is to help decrease the prevalence of sexually transmitted diseases (STD) in adolescents. The prevalence of STD is a variable dependent on factors such as sexual behaviour, contraceptive knowledge and practice of the girls. These have been discussed in previous reports. ${ }^{267}$ It is difficult to document the prevalence of STD in adolescents because of confounding variables, such as location (urban or inner city); selected or unselected population; and composition of studied groups, boys, girls or both. In a report on an unselected group of male and female adolescents ${ }^{2}$ the prevalence of STD was higher in the adolescents than in the adults. However, in another report on a selected group of adolescent girls in care ${ }^{7}$ only a core group of girls $(37 \cdot 1 \%)$ contributed all the positive results. Our study reports on a selection of girls who had voluntarily attended the GUM clinic and the results show that the prevalence of STD is similar in adolescent girls and adult females.

There was no difference between the girls and the adults in their number of sexual partners in the preceding three months. However, bacterial vaginitis and gonorrhoea were significantly higher in the girls than in the adults. The two groups also differed in their use of contraceptives. Nearly half $(49 \%)$ of the adolescent girls were not using any form of contraceptives. This number is unacceptably high, and in addition only $15 \%$ of adolescent girls used condoms or caps. We believe that sexually active adolescents should be encouraged to use barrier contraceptives. These should protect against STD and unwanted pregnancies. ${ }^{689}$

Another important contributing factor to the prevalence of STD in adolescent girls involves the sexual lifestyle of their male partners. Our study has shown that some adolescent girls in this city are associating with male partners who are older, who have multiple partners and who have a higher prevalence of genital infections. Contacting the male partners of these girls for treatment and health education should be given high priority. Developing such a programme will hopefully be a positive step in making adolescent sexuality healthier.

Adolescent sexuality and its consequences like STD, unwanted pregnancies, school age mothers still constitute a challenge to medical specialities and the community at large. By liasing and co-operating with school authorities, youth clubs and other medical specialities, the GUM speciality can play a vital role in adolescent sexuality.

We thank the Consultants Dr J C Clay and Dr M Shahmanesh for giving us permission to review the notes and helpful suggestions, $\mathrm{Mr}$ John Belcher for statistical analysis and Miss Pamela Tilstone for typing this manuscript.

Table 2 Infective agents in girls, controls and males

\begin{tabular}{|c|c|c|c|c|c|}
\hline & & Girls $(n=159)$ & Controls $(n=215)$ & Males $(n=55)$ & p value \\
\hline $\begin{array}{l}\text { i) } \\
\text { ii) } \\
\text { iii) } \\
\text { iv) }\end{array}$ & $\begin{array}{l}\text { None } \\
\quad 1 \\
>2 \\
\text { Prevalence of infection }\end{array}$ & $\begin{array}{l}37 \quad(23 \cdot 3 \%) \\
61 \quad(38 \cdot 4 \%) \\
61 \quad(38 \cdot 4 \%) \\
76 \cdot 7 \%\end{array}$ & $\begin{array}{l}46 \quad(21 \cdot 4 \%) \\
92 \quad(42 \cdot 8 \%) \\
77(35 \cdot 8 \%) \\
78 \cdot 6 \%\end{array}$ & $\begin{array}{l}4 \quad(7 \cdot 3 \%) \\
41 \quad(74 \cdot 5 \%) \\
10(18 \cdot 2 \%) \\
92 \cdot 7 \%\end{array}$ & $\begin{array}{l}\chi^{2}=22.86 \\
\mathrm{df}=4 ; \mathrm{p}<0.001\end{array}$ \\
\hline
\end{tabular}




\section{Address correspondence to: Dr Opaneye.}

1 Foster GE, Robinson GE, Munday PE. STDs: An epidemic among adolescent girls? $B r J$ Venereal Dis 1984;60:402-5.

2 Thin RN, Whartley JD, Blackwell AL. STD and contraception in adolescents. Genitourin Med 1989;65:157-60.

3 Shafer MA, Irwin CE. Acute salpingitis in the adolescent female. $J$ Paediatrics 1982;100:339-50.

4 Golden N, Hammerschleg M, Neuhoff S, Gleyzer A. Prevalence of chlamydia trachomatis cervical infection in female adolescents. Am J Dis Child 1984;138:562-4.

5 Barron SL. Sexual activity in girls under 16 years of age. $\mathrm{Br} J$ Obstet Gynaecol 1986;93:783-93.

6 Zelnick M, Kartner JF. Sexual activity, contraceptive use and pregnancy among metropolitan teenagers 1971-1979. Fam Plann Persp 1980;12:230-7.

7 Mulcahy FM, Lacey CJN. Sexually transmitted infection in adolescent girls. Genitourin Med 1987;63:119-21.

8 Hardy PH, Hardy JB, Nell EE, Graham DA, Spence MR, Rosenbaum RC. Six sexually transmitted disease agents among pregnant inner city adolescents and pregnancy outcome. Lancet 1984;ii:333-7.

9 Ashken IC, Soddy AG. Study of pregnant school age girls. $\mathrm{Br} J$ Fam Plann 1980;6:77-82.

10 Hermman-Giddens ME, Gutman LT, Berson NL, and the Duke Child Protection Team. Association of co-existing vaginal infection in multiple abusers in female children with genital warts. Sex Transm Dis 1988;15:63-7.

11 Robinson GE, Forster GE, Munday PE. The changing pattern of STD in adolescent girls. Genitourin Med 1985;61:130-2.

12 DeBuono BA, Zinner SH, Daamen M, McCormack WM. Sexual behaviour of college women in 1975, 1986 and 1989. N Engl J Med 1990;332:821-5.

Accepted for publication 10 December 1990 